\title{
Control and Protection of Power Electronics Interfaced Distri- buted Generation Systems in a Customer-Driven Microgrid
}

\author{
Fang Z. Peng, Yun Wei Li and Leon M. Tolbert
}

\begin{abstract}
This paper discusses control and protection of power electronics interfaced distributed generation (DG) systems in a customer-driven microgrid (CDM). Particularly, the following topics will be addressed: microgrid system configurations and features, DG interfacing converter topologies and control, power flow control in grid-connected operation, islanding detection, autonomous islanding operation with load shedding and load demand sharing among DG units, and system/DG protection. Most of the above mentioned control and protection issues should be embedded into the DG interfacing converter control scheme. Some case study results are also shown in this paper to further illustrate the above mentioned issues.

Index Terms-Distributed generation (DG); renewable energy source (RES); micro-source; microgrid; customer-driven microgrid (CDM), power electronics; power converters; DG protection; grid-connected operation; islanding operation; autonomous operation.
\end{abstract}

\section{INTRODUCTION}

Distributed generation (DG) is becoming an increasingly attractive approach to reduce greenhouse gas emissions, to improve power system efficiency and reliability, and to relieve today's stress on power transmission and distribution infrastructure. In recent years, DG systems based on renewable energy source (RES) or micro-sources such as fuel cells, photovoltaic (PV) cells, wind turbines, and micro-turbines are experiencing a rapid development, due to their high efficiencies and low (or zero) emissions. The micro-source based DG also presents a challenge in terms of interaction to the grid, where the power electronic technology plays a vital role $[1,2]$.

The development of DG has lead to a more recent concept called microgrid [3], which is a systematic organization of DG systems. Compared to a single DG, a microgrid has more capacity and control flexibilities to fulfill system reliability and power quality requirements. The microgrid also offers opportunities for optimizing DG systems. A typical example is the combined heat and power (CHP) generation or cogeneration, which is currently the most important measure to improve energy efficiency. For the CHP applications, the heat producing generation units and non-heat producing units in the microgrid can be optimally placed with the siting flexibilities of DG units [4]. Furthermore, the microgrid can operate in gridconnected mode or autonomous islanding mode and benefit both the utility and the customers.

A customer-driven microgrid (CDM) is expected to fully

This work was supported in part by the National Science Foundation (USA) under CNS 0831165 and NSF-CNS-0831466, and National Science and Engineering Research Council (Canada) under Grant No. 355773.

F. Z. Peng is with Department of Electrical and Computer Engineering, Michigan State University, East Lansing, MI 48824 USA (fzpeng@egr.msu.edu).

Y. W. Li is with Department of Electrical and Computer Engineering, University of Alberta, Edmonton, AB T6G 2V4 Canada (yunwei.li@ece.ualberta.ca).

L. M. Tolbert is with Department of Electrical Engineering and Computer Science, University of Tennessee, Knoxville, TN. (tolbert@utk.edu) embrace all these benefits that a microgrid and DG can provide. Since the micro-source based DGs are normally controlled and connected to the grid through power converters, by coordinating and controlling individual DG through the power electronics interface, the microgrid has significant control flexibility to fulfill system requirements in terms of efficiency, security, reliability, power quality, etc. In addition, a microgrid with collective actions of DGs can provide many ancillary services to the upper-stream power system through proper control and communication.

Proper operation of a microgrid requires advanced local voltage control and power flow/sharing control. Moreover, system protection has to be carefully coordinated with each DG and short circuit current has to be limited through the proper control of DG units in a microgrid. To address the operation and control issues of a power electronics interfaced CDM system, in the following sections, we will discuss: microgrid system configurations and features that are distinctively different from today's distribution systems, DG interfacing converter configurations and their control, DG power flow control during grid-connected operation, islanding detection and operation, load demand sharing among DGs, and system/DG protection. Case studies are provided to illustrate the operation and protection of a CDM system.

\section{MicROGRID SYSTEM CONFIGURATIONS AND FEATURES}

In a broader and more futuristic view, a microgrid is a tiny power system with a cluster of loads and distributed generators operating together through an energy manager and flexible ac transmission system (FACTS) control devices (such as power flow controllers, voltage regulators, etc.), and protection devices. A microgrid itself can be a dc grid [5] or ac grid (or even a high frequency ac grid [6]). An ac microgrid can be a single-phase or a three-phase system. It can be connected to low voltage or medium voltage power distribution networks. This paper only considers ac microgrids that are connected to a distribution system of the utility power grid and serve as a part of the distribution system.

Fig. 1 shows an illustration of such a microgrid, where several DG units, including a PV system, a wind power system, two micro-turbine systems and a fuel cell system, are connected to the distribution feeders. The microgrid is then connected to the mains grid through a separation device (normally a static transfer switch, STS) at the point of common coupling (PCC), which ensures fast disconnection of the microgrid from the utility in case of a utility fault. More simply put, a microgrid can be viewed as a distribution system with power generators and control devices. As shown in Fig. 1, an energy manager serves as the control center for the microgrid. This energy manager, together with the protection coordinator and power quality controller/monitor, maintain the reliable opera- 


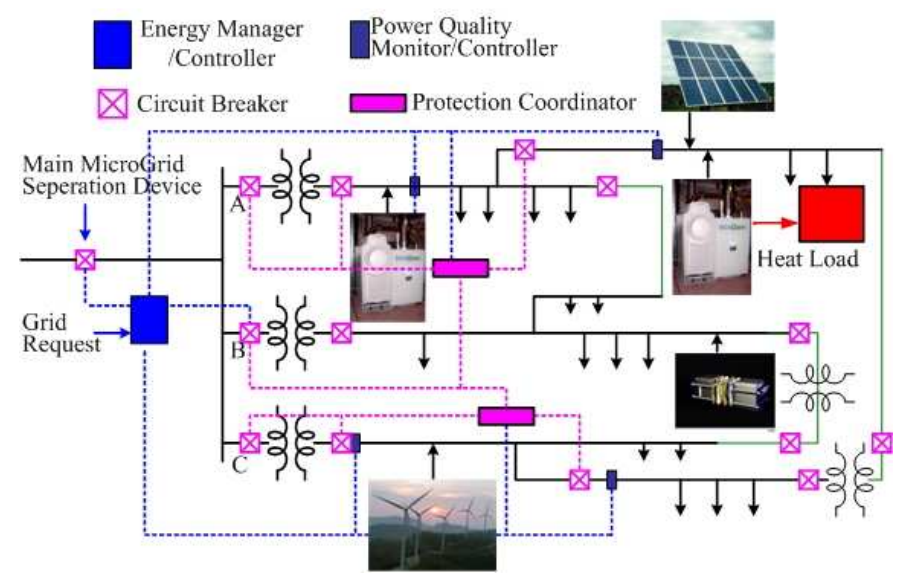

Fig. 1. Microgrid system configuration and main features.

tion of the microgrid and respond to the mains grid's request. Another main feature of a microgrid, especially a CDM, is that the distribution network can be configured to a ring structure as shown in Fig. 1 with added connections, thus the system reliability can be greatly enhanced.

Because of their vicinity to loads, DGs such as the fuel cell and the micro-turbine based units can be used to provide CHP generation with improved overall efficiency. With an energy storage device connected, the fuel cell based DG system can also produce controllable output power to meet grid or load transient requirements. The wind and PV based DG systems are normally controlled with maximum power point tracking (MPPT) from the wind turbines and PV panels to maximize the energy generation. Similarly, with energy storage systems, the wind and PV DG systems can also produce controllable output power to facilitate the dispatched power generation and load demand matching. As a result, the microgrid provides an opportunity to optimize the utilization of energy with improved overall thermal and electrical efficiencies by properly locating different generation units with consideration of the geographical conditions and the different types of loads.

There are two operation modes for a microgrid: gridconnected mode and islanding mode. When connected to the utility grid, the main function of the DG units is to generate power and provide local voltage and power support. With the interfacing power converters, controllable reactive power can also be produced by the DG units. As a result, the line loss can be reduced and the overall system efficiency can be greatly improved. Note that the reference real and reactive power of each DG can be commanded by the microgrid energy manager, or DGs can be commanded and controlled at their maximum power available through MPPT as in a PV or wind DG.

The other operation mode is the intentional islanding mode. This happens when the microgrid is cut off from the main grid (e.g. during power outage of the main grid) and continues to operate to provide power to local loads. Islanding operation is a very important function of the CDM. For a reliable islanding operation, the DGs have to be controlled to meet the following three requirements. First, the collective power generation from all the DGs in the microgrid has to match the load demand. Therefore, accurate load sharing among the DG units accord- ing to each DG's power capacity is important to avoid possible damage to any DG. Second, the DGs have to provide voltage control to ensure all feeders' voltages are within their normal ranges. Third, all DGs have to be synchronized with each other and provide microgrid frequency control. Due to different control objectives of the two operation modes, a fast and reliable islanding detection scheme is also important for each DG unit to ensure the proper operation of a microgrid.

To ensure a smooth re-connection of the microgrid back to the main grid when the grid recovers from a fault, a microgrid re-synchronization method is also required. When the main is back on, the microgrid has been operating in the islanding mode and has its own PCC terminal voltage magnitude, frequency and phase angle, which most likely are different from those at the main grid terminal. A re-synchronization scheme is thus needed before closing the separation switch. The resynchronization is to ensure the voltage magnitude, frequency and phase angle at the microgrid end and main grid end match for a smooth reconnection of the two systems.

Finally, protection is another critical aspect of a microgrid. New protection schemes and coordination methods are required for a microgrid to respond immediately to the faults in the utility or within the microgrid. This is because traditional distribution system protection methods may not work for microgrids due to its radical change from the radial distribution system structure. Moreover, with the presence of power electronics in the DG system, where the semiconductor device rating is typically $2-3$ times of the rated current, the traditional over-current protection scheme is no longer suitable in a microgrid. Furthermore, the conventional protection scheme at distribution network will be seriously affected because of the connection of DGs, as each DG will contribute to and increase fault current of the system. Therefore, the microgrid fault protection has to be re-coordinated and the fault current has to be re-evaluated and limited accordingly and preferably by DGs.

\section{DG INTERFACING POWER ELECTRONICS}

Generally, micro-sources are dc or non-utility-grade ac, whose voltage/current has to be converted to utility-grade ac with the desired magnitude, frequency, and phase angle through the interfacing power converters. Furthermore, unlike conventional rotating machines based DG, the power electronics interfaced DG usually need an energy storage system to handle the grid transient or load demand change, especially when the microgrid is operating in islanding mode. With today's increased penetration of DG, the power electronic interfaces are subject to the requirements related to the energy source characteristics, the energy storage system, the distribution system configuration, power quality, etc. [2].

Fig. 2 shows a diagram of a power electronics interfaced DG system, where the energy source is interfaced to the local loads and utility system through a voltage source inverter (VSI). Note that for different microgrid voltage levels and system configurations, different interfacing converter topologies can be employed with the associated PWM technique implemented. An energy storage system is usually connected to the dc link of the interfacing inverter to enable the DG unit to produce controllable output power. The energy storage sys- 


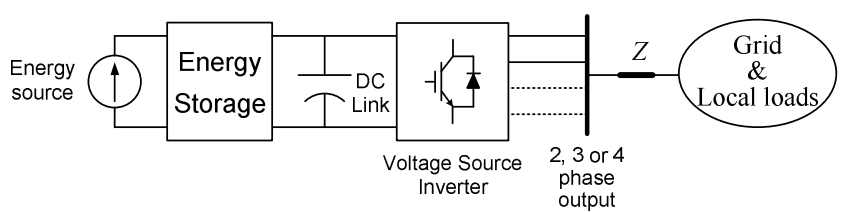

Fig. 2. Diagram of a typical power electronics interfaced DG system.

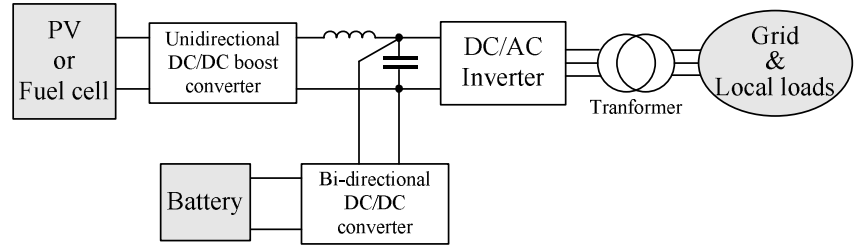

Fig. 3. A PV or fuel cell grid-connected DG system with energy storage.

tem can be in the form of batteries, supercapacitors, flywheels, superconductors, etc, which is also interfaced to the system through a power converter for energy charging/discharging.

A more detailed power electronics system in a PV or a fuel cell system (where the output of both energy sources is dc) is shown in Fig. 3. In this system, a unidirectional dc-dc boost converter is employed to boost the dc output from the energy source to a level that is optimized for the inverter. The MPPT for a PV system or optimal efficiency operation for a fuel cell system is normally realized at this boost converter stage [7, 8]. The bidirectional dc-dc converter in Fig. 3 functions by charging and discharging the battery to enable controllable output power generation in the grid-connected mode and load demand matching in the islanding operation.

The interfacing converters can have single-stage, doublestage or multiple-stage configurations. Fig. 4 (a) and (b) illustrate the dc-ac conversion for a PV or fuel cell system with a single-stage dc-ac converter or double-stage converter system using a dc-dc converter followed by a dc-ac converter. Normally the single-stage topology needs an overrated inverter and high dc output voltage from the PV panel or fuel cell stack, and features high efficiency while suffering from limited power capacity, compromised output quality and limited operation range [9]. The recently proposed $\mathrm{Z}$ source converter topology with embedded voltage boost function can be a good candidate for this single-stage conversion $[10,11]$. On the other hand, the two-stage topology employs a dc-dc converter to boost the dc link voltage and at the same time realizes the MPPT or other desired functions. When electrical isolation is required, the isolation transformer can be at the line frequency ac side (as in Fig. 3) or within the high switching dc-dc converters (such as flyback, push-pull dc-dc converters etc.). Generally, the isolation at dc-dc converter stage is preferred due to the reduced weight and size benefited from the much higher transformer operating frequencies.

The power electronics interfaces for a micro-turbine or wind turbine generator system can be two-stage converters or multi-stage converters. Fig. 5 shows the ac-dc-ac conversion process in a micro-turbine or wind-turbine system with twostage converters using ac-dc rectifier and dc-ac inverter or multi-stage conversion with ac-dc, dc-dc and dc-ac converters. A typical two-stage dc-ac conversion with a dc-dc boost converter and a dc-ac single phase VSI is shown in Fig. 6. It is a

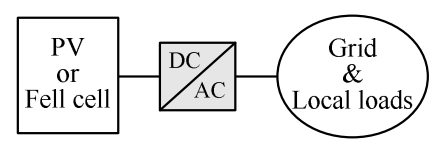

(a)

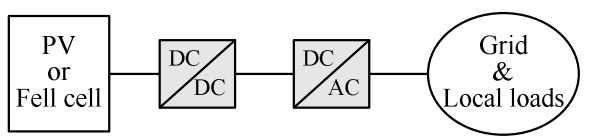

(b)

Fig. 4. Power electronics interfaces for a PV or fuel cell DG system with: (a) single stage dc-ac conversion and (b) dc-dc and dc-ac two-stage conversion.

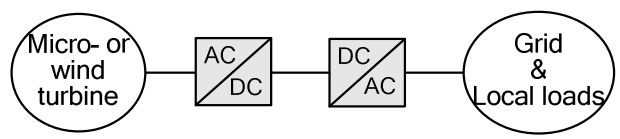

(a)

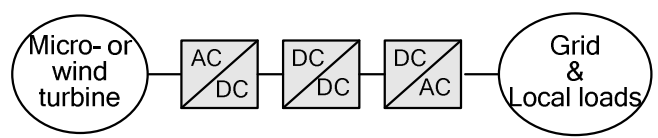

(b)

Fig. 5. Power electronics interfaces for a micro-turbine or wind turbine DG system with: (a) ac-dc and dc-ac two-stage conversion and (b) multi-stage conversion.

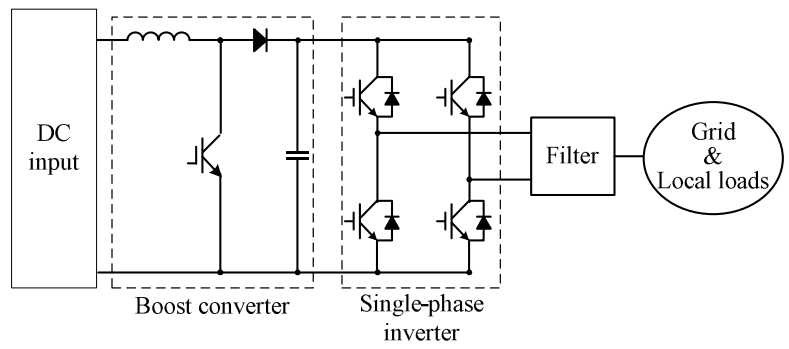

Fig. 6. A two-stage dc-ac conversion system with a boost dc-dc converter and a buck dc-ac inverter.

popular topology for small wind turbine systems [9], where the front end ac-dc converter is usually a diode rectifier bridge. A similar topology with three-phase grid interfacing inverter can be used for larger wind turbine systems, where a synchronous wind turbine generator through a three-phase diode rectifier (with ac-dc, dc-dc and dc-ac multi-stage conversion) can be more cost effective compared to an induction generator with a two-stage ac-dc and dc-ac power electronics interface using PWM rectifier and inverter [2].

With the development of power electronics technologies, the multilevel converters based interfaces are becoming more attractive. One reason is that PV systems can easily provide different dc voltage levels with the modular structure of PV arrays. On the other hand, the trend of larger wind turbine systems also makes the use of high power multilevel converters a natural choice because of the better harmonic performance and low switching losses. Some popular multilevel converters used in DG systems are neutral point clamped (NPC) converters, cascaded H-bridge converter, etc. Finally, note that some other interfacing converter topologies such as ac-ac matrix converter, soft-switching converters etc, have also been seen in DG. 


\section{GRID-CONNECTED OPERATION AND DG POWER FLOW CONTROL}

The control of a microgrid involves many challenging issues. In order to operate a microgrid properly in different operation modes and during operation mode transitions, good power management strategies including real and reactive power control, frequency and voltage regulation, synchronization, load demand matching, etc., should be developed. This section discusses the power flow control for a microgrid in the grid-connected operation mode. The islanding operation and related issues will be addressed in Section V.

In the grid-connected operation mode, the main function of a DG unit is to control the output real and reactive power, where the real power reference can be given from the microgrid energy management controller or can be determined with MPPT. On the other hand, the reactive power reference can be zero for unity power factor injection or commanded according to grid reactive power or voltage requirement $[3,12,13]$. The real and reactive power generated by a DG can be controlled through current or voltage regulation, thus the DG output power control schemes can be generally categorized as current-based and voltage-based power flow control.

\section{A Power Flow Control through Current Regulation}

Fig. 7 shows the power control scheme (with unity power factor) through current regulation. As illustrated, the reference current magnitude is obtained from the real power control loop, where the real power reference can be produced from the MPPT (like in a wind or PV system), the maximum system efficiency control (like in a fuel cell system [8]) or from the command value of the energy manager. To improve the transient performance, a current magnitude feedforward loop can be added, where the feedforward current is calculated from the reference power and grid voltage magnitude. With the grid voltage angle information from a phase-locked-loop (PLL), the reference three-phase inverter output current synchronized to the grid voltage can be obtained. The DG output current is then controlled in a closed loop manner to track the current reference.

If both real and reactive power flow control is desired, the real power control loop can be used to produce the synchronous frame d-axis reference current (same as the current magnitude generation in Fig. 7) and the reactive power control loop can be employed to produce the q-axis current [13]. The synchronous d-q frame current can then be controlled in a closed loop manner as shown in Fig 8. Note that similar current control performance can also be obtained in stationary frame by transforming the $\mathrm{d}-\mathrm{q}$ reference current into stationary frame and using P+Resonant current controller [14-16].

In case of an ac-dc-ac interfacing converter topology for most turbine generators, the real power is usually controlled in the rectifier (which actually controls the generator speed and provides power control or MPPT function), and the real power output of the inverter can be slightly regulated to maintain a constant dc link voltage (where the power difference between the rectifier input and inverter output can be used to charge or discharge the dc link capacitor). A similar scenario is also

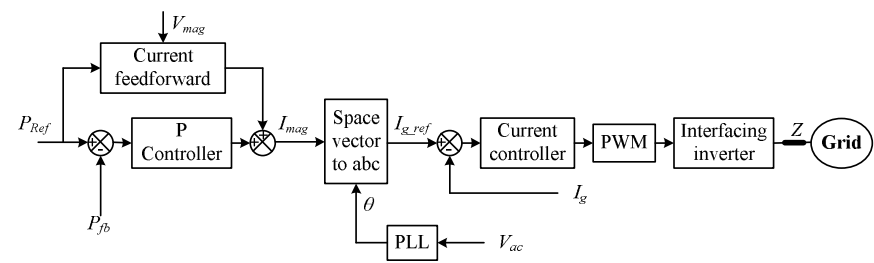

Fig. 7. Grid-connected power flow control scheme through output current regulation (with unity power factor).

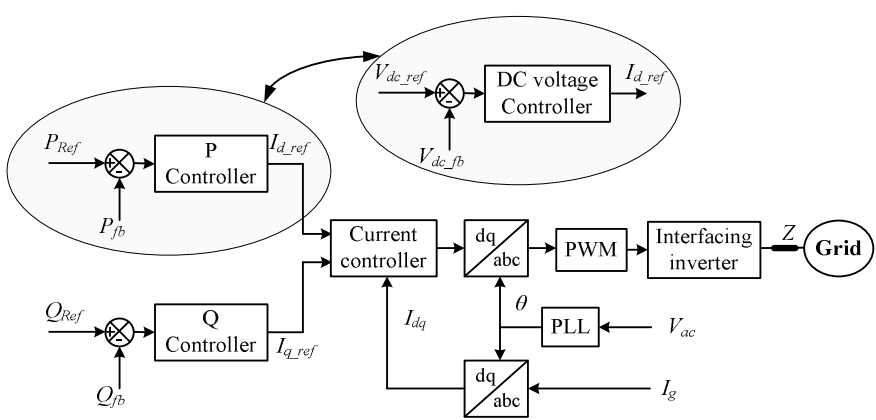

Fig. 8. Grid-connected real and reactive power control scheme through output current regulation.

applicable to a PV or fuel cell double-stage converter system, where the front end dc-dc converter usually controls the system input power, while the inverter is used to regulate the $\mathrm{dc}$ link voltage by slightly adjusting the system output power. In this case, the dc link voltage reference instead of the real power can be used in the interfacing inverter to generate the d-axis reference current as shown in Fig. 8 [16, 17].

\section{B Power Flow Control through Voltage Regulation}

The other power flow control method is based on regulating the DG output voltage. This power control method is related to the real and reactive power flows between two nodes (DG voltage, $V_{1} \angle \delta$ and PCC voltage, $\left.V_{g} \angle 0\right)$ separated by a line impedance $(Z=R+j X)$, normally resulted from a transformer and/or and LC in between, as illustrated in (1) and (2):

$$
\begin{aligned}
& P=\frac{V_{1}}{R^{2}+X^{2}}\left[\left(R\left(V_{1}-V_{g} \cos \delta\right)+X V_{g} \sin \delta\right]\right. \\
& Q=\frac{V_{1}}{R^{2}+X^{2}}\left[-R V_{g} \sin \delta+X\left(V_{1}-V_{g} \cos \delta\right)\right]
\end{aligned}
$$

where $V_{l}$ and $V_{g}$ are the respective magnitudes of the two voltages and $\delta$ is the phase angle difference between the two voltages. For a mainly inductive line (or filter) impedance with high $\mathrm{X} / \mathrm{R}$ ratio, the resistance $(R)$ may be neglected. Further considering that the phase angle difference $\delta$ is typically small, it is reasonable to assume $\sin (\delta)=\delta$ and $\cos (\delta)=1$. As a result, it can be concluded that the flow of real power $P$ is proportional to the phase angle difference $(\delta)$ and the flow of reactive power $\mathrm{Q}$ is proportional to the voltage magnitude difference $\left(V_{l}-V_{g}\right)$. With the above relationship, the DG output real power can be controlled by regulating the DG output voltage phase angle $\delta$, while the DG output reactive power can be regulated by controlling the DG output voltage magnitude. This method could be used in both the grid-connected and islanding operation modes [3, 12, 13, 18, 19]. 


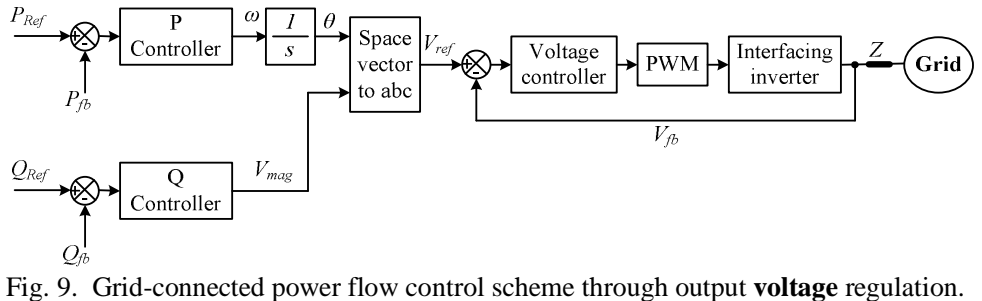

Fig. 9 shows the control scheme with DG output voltage regulation. It can be seen that the real power controller produces the reference output voltage phase angle while the reactive power controller generates the reference voltage magnitude. The phase angle and magnitude are then transformed to the three-phase reference voltage. Note that although a single voltage closed-loop control is illustrated in Fig. 9, an inner current loop can be designed to be embedded in the voltage loop to improve both the transient and stability performances $[12,20]$. In Fig. 9, a proportional controller are used for the real and reactive power controllers to realize the real power versus system frequency $(P-\omega)$ droop and the reactive power versus voltage magnitude $(Q-V)$ droop characteristics $[3,18]$. However, to improve the reactive power control accuracy in grid-connected operation mode, integral control can be included into the reactive power controller [12, 21, 22].

Compared to the power control through current regulation, the voltage regulation method is more sensitive to the line impedance between the DG and the PCC. The small line impedance in the denominators of (1) and (2) will cause significant power flow even with a slight variation of the DG output voltage. Furthermore, the low X/R line impedance ratio at a low voltage microgrid can also cause real and reactive power control couplings if the DG unit is directly coupled to the microgrid without grid side inductor or transformer. This can be noticed from (1-2), where if the line impedance is not mainly inductive, the voltage magnitude and phase angle will have non-negligible effects on the real and reactive power flows respectively. To improve the power control performance, physical inductor can be added at the DG output [19, 23]. Alternatively virtual power control frame [24, 25], or virtual DG output impedance $[24,26-28]$ can be realized through the interfacing inverter control scheme.

On the other hand, an obvious advantage of the voltage regulation scheme is that a similar voltage control strategy can be used in islanding microgrid operation for load demand sharing between the DG units (by employing the $P-\omega$ and $Q-V$ droop method). Sharing the same control strategy in different operation modes will ensure smooth transients during operation mode transitions. More discussion of the load demand sharing in islanding operation will be discussed in Section V.

Furthermore, due to the grid interfacing nature, a microgrid is subject to all kinds of utility power quality events. According to the present grid codes, the DG/microgrid should ride through these power quality events in order to improve the system stability. To meet this grid fault ride-through requirement, different control strategies such as positive sequence component control, reactive power control, etc. were discussed in [16]. In addition, a dual-inverter grid interfacing

conditioner, where a series inverter is used to compensate the grid power quality disturbances, was proposed in [29].

\section{INTENTIONAL ISLANDING OPERATION AND LOAD DEMAND SHARING}

The intentional islanding mode is very important for microgrids to continue to provide power to critical loads during power outage of the main grid. During the grid-connected operation, each DG system in a microgrid is usually operated with the power flow control in the presence of a stiff grid voltage as has been discussed. When the microgrid is disconnected from the mains grid, each DG unit has to detect this islanding situation and switch its control scheme from power control mode to voltage control mode and provide a constant voltage to local loads.

Besides the control mode difference, there are several other issues to be considered for islanding operation, such as synchronization among the DG units, the power flow constraint due to the DG capacity, voltage/frequency variations and thermal constraints of the distribution feeders. The islanding operation is further complicated when considering the large variation of electrical distance between DG units even within a small geographical area. E.g. for direct coupled DG units, the impedance between two DGs is just the low voltage distribution feeder, which has very small inductance and low X/R ratio. While in case of DG units with LCL output filters (with $3 \sim 10 \%$ grid side inductance) and/or with transformers (with $3 \sim 10 \%$ leakage inductance), the equivalent electric distance among DGs is comparable to medium and long transmission lines. (The 12 to $40 \%$ inductance with both grid side inductor and transformer between two DGs is equivalent to over 160 kilometers of transmission line, which is the average transmission distance in North America). To address these various challenges in microgrid intentional islanding operation, islanding detection, load shedding, load demand sharing with synchronized DG unit operation are discussed in this section.

\section{A Islanding Detection and Load Shedding}

There are various islanding detection methods proposed for DG systems [31]. Since the DGs are in power control mode when connected to the grid, any power imbalance between DG generation and load demand will result in voltage magnitude (and frequency) changes when islanding occurs, regardless of whether the power control is through current or voltage regulation. Fig. 10 shows the case study results of rapid voltage magnitude changes when the microgrid is cut off from the main grid. The voltage change rate and profile are determined by the amount of power differences and control parameters of the DG. We have demonstrated that the detection methods based on voltage (and/or frequency) changes at islanding in- 


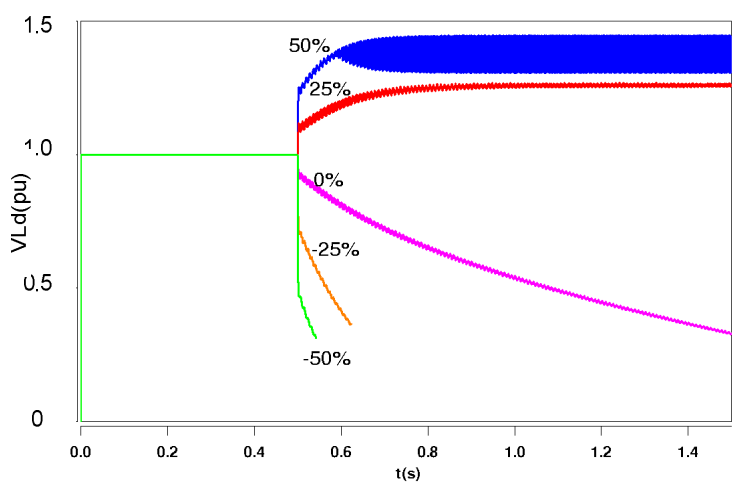

Fig. 10. Voltage amplitude during islanding transient with different real power imbalances $(\Delta \mathrm{P})$ and a fixed reactive power difference $(\Delta \mathrm{Q}=0)$.

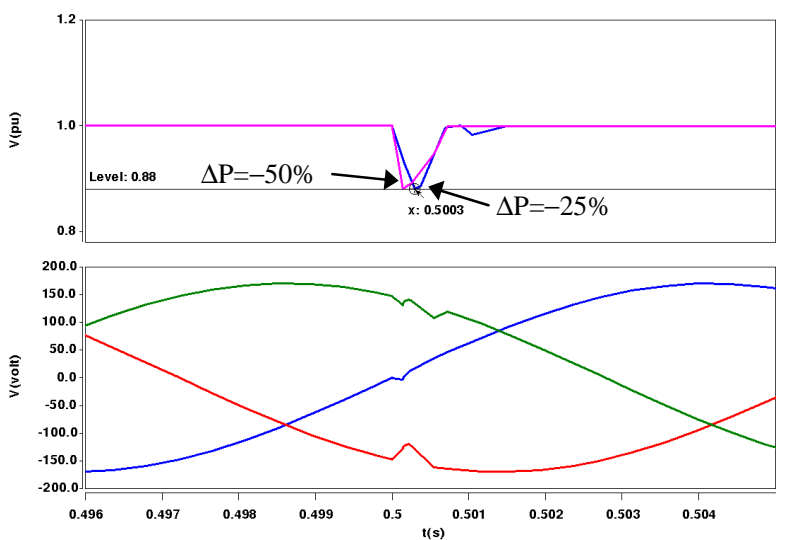

Fig. 11. Voltage amplitude (with $\Delta \mathrm{P}=-25 \%$ and $-50 \%$ ) and three phase voltage waveforms (with $\Delta \mathrm{P}=-25 \%$ ) during an islanding transition.

stant are effective and the islanding operation can be successfully detected by monitoring DG or microgrid terminal voltage before the voltage reaches pre-determined limits (e.g. $0.88 p u$ to $1.1 p u$ ). Although there will be a non detection zone (NDZ) with this voltage magnitude or frequency detection method if the power difference is too small, this NDZ can be eliminated by employing some additional detection algorithms (e.g grid impedance detection). While serving as good indications for islanding detection, the quick voltage and frequency variations lead to a serious concern: the microgrid would operate out of the allowable voltage or frequency range quickly after islanding occurs. To avoid this, intelligent load shedding algorithms need to be implemented in a microgrid system to make sure that the demand is within available generation by disconnecting some least important loads.

The approach for intelligent load shedding is to detect the voltage change rate and profile after the main power outage and determine the minimum amount of load to be shed before switching to the voltage control mode for islanding operation. The voltage change rate can be determined for a given power control method in grid-connected mode by first obtaining the voltage-power expression and then its derivative, from which the amount of load to be shed can be calculated [32]. Fig. 11 shows a smooth transition from the constant power control (through current regulation) to voltage control with the intelligent load shedding based on the voltage behavior for a preoutage power mismatch of $\Delta \mathrm{P}=-25 \%$ and $-50 \%$ respectively.

\section{B Load Demand Sharing Between DG Systems}

Another major issue in islanding operation is the synchro-

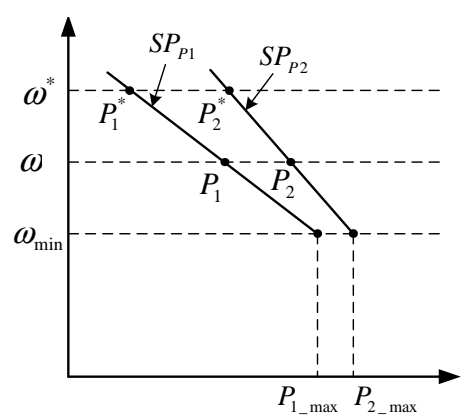

Fig. 12. $P$ - $\omega$ droop slopes for two DG units.

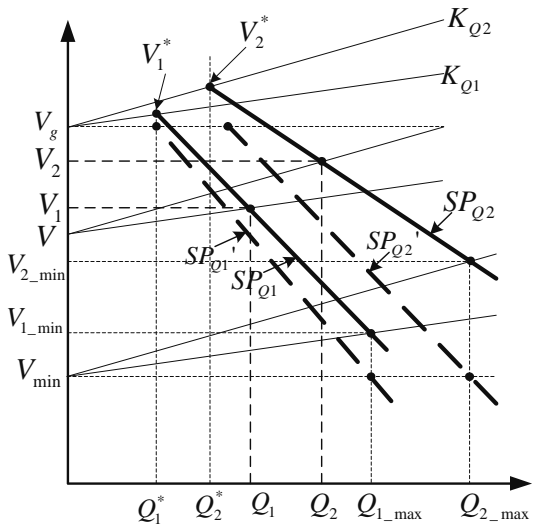

Fig. 13. $Q-V$ droop slopes for two DG units.

nization and proper load demand sharing among the DG units. During the grid-connected operation, the stiff main grid provides a relatively constant frequency reference to all DGs. When islanding occurs, the DGs have to control the frequency collectively and synchronize with each other. Without a dominant stiff source, frequency control and synchronization become challenging. On the other hand, the load demand sharing among the DG units according to their respective power capacities is important. This frequency/voltage control and load demand sharing can be achieved through the frequency and voltage droop control [18], that is, the DG units can emulate the parallel synchronous generators in a traditional power system and automatically share the total load demand.

As discussed in Section IV(B), assuming a mainly inductive line impedance, the real and reactive power output of each DG unit can be controlled by the DG output frequency and voltage magnitude respectively. To ensure the DG units in a microgrid can share the load demand proportionally according to their capacities, the P- $\omega$ droop and Q-V droop characteristics can be introduced into the DG voltage control scheme. Fig. 12 shows the P- $\omega$ droop diagram of two DG units, where $\mathrm{P}_{1 \max }$ and $\mathrm{P}_{2 \max }$ are the maximum possible output real powers of two DGs, $\mathrm{P}_{1}{ }^{*}$ and $\mathrm{P}_{2}{ }^{*}$ are the reference powers in the gridconnected mode. The droop slope of each $\mathrm{DG}$ unit $\left(\mathrm{SP}_{\mathrm{P} 1}\right.$ or $\mathrm{SP}_{\mathrm{P} 2}$ ) can be determined in such a way that the DG produces its reference output power at the grid frequency $\left(\omega^{*}\right)$ and its maximum possible output power at the minimum allowable frequency $\left(\omega_{\min }\right)$. By changing their output frequency according to their respective $P$ - $\omega$ droop slope, the two DG units can share the load demand properly. The reactive power sharing can be realized in a similar manner by implementing the $Q-V$ droop into the DG unit control scheme. Note that the droop 
characteristics can be implemented by simply using the calculated frequency and voltage droop slopes in the real and reactive power controllers of Fig. 9.

Developed based on the predominantly inductive line impedance, the droop method, however, is subject to a number of drawbacks when implemented for a low voltage microgrid which include the power coupling due to low $\mathrm{X} / \mathrm{R}$ ratio of line impedance and the reactive power sharing accuracy due to unequal DG output voltage magnitude. The low $\mathrm{X} / \mathrm{R}$ ratio exists between directly coupled DG units without output transformers or grid side inductors. Therefore the power coupling issue also appears in grid-connected mode operation when the power flow control using voltage regulation is used as discussed earlier. To decouple the real and reactive power flow, a physical inductance $[19,23]$ or variable virtual impedance [24] can be implemented. Alternatively decoupled virtual power control [24] or voltage and frequency frame power control [25] can used.

The inaccurate reactive power sharing problem is illustrated in Fig. 13, where it can be seen that with equal DG output voltage magnitude, the droop slope of each DG unit will be calculated as the dashed lines. However, with a mainly inductive impedance at the DG output (which can be either a physical inductance or virtual one through control), the DG output voltage magnitude increases approximately linearly with the reactive power. In other words, with the same line impedance, unequal reactive power flow leads to different DG output voltages. This is different from the real power flow control, where all the DG units in a microgrid will operate at the same frequency, leading to zero steady state error for real power control/sharing. This also implies that an integral controller of reactive power is required in grid-connected operation mode to ensure accurate reactive power control with zero steady state error as mentioned in Section IV (B).

To improve the load demand sharing accuracy in intentional islanding microgrid operation, an additional signal can be generated through the interfacing inverter and the signal frequency can be controlled for accurate reactive power sharing [30]. This method, however, is complex and will produce voltage distortions (harmonics) in the microgrid. Another method to improve the reactive power sharing accuracy is based on the combination of virtual inductance control and accurate $Q-V$ droop slope estimation [28]. By using this method, the accurate $Q-V$ droop slopes as shown in the solid lines in Fig. 13 can be obtained, where $\mathrm{V}_{1} *, \mathrm{~V}_{2} *, \mathrm{~V}_{1}, \mathrm{~V}_{2}, \mathrm{~V}_{1 \_ \text {min }}$ and $\mathrm{V}_{2 \_ \text {min }}$ are the voltages during grid-connected operation, islanding operation and minimum allowable voltages for the two DG units, respectively. $\mathrm{K}_{\mathrm{Q} 1}$ and $\mathrm{K}_{\mathrm{Q} 2}$ are the estimated $\mathrm{V} / \mathrm{Q}$ slopes for the two respective DG units. More details of this reactive power sharing approach can be found in [28].

\section{SYSTEM AND DG PROTECTION}

Short circuits can endanger personnel as well as power system and customer equipment. Excessively high or low voltages can also damage equipment. To avoid these damages, protective relays are installed to detect the abnormal conditions and to open circuit breakers and isolate the problem. Proper action is generally required within a few fundamental cycles, a time frame that is too fast for central control. For this reason, decisions are often made autonomously by local devices based upon locally available information (e.g. excessive currents or out of range voltages). These functions may be performed faster, better, and cheaper with the aid of power electronics or advanced sensors and controllers. This may be especially true if the protective functions can be built into the control systems of DG.

Traditional synchronous generators can inherently provide high short circuit fault currents. Also traditionally, this high fault current property has been used in the protective relaying schemes in order to detect short circuits. This excessive fault current that appears before the opening of breakers is harmful to sensitive loads and power electronics devices. On the other hand, limiting fault currents is a unique capability of power electronics interfaced DG and this can provide a major benefit considering the high cost of high fault current interrupting circuit breakers. Power electronics have the capability of sensing faults almost instantaneously and take action before high levels of fault current begin to flow. This kind of fault current limiting function, if built into DG correctly, will make system coordination and protection much simpler, and the current carrying and interrupting equipment less expensive. During a fault, DG can be controlled to be a voltage reduction device or an impedance alteration device to limit fault current.

Another issue related to protection is fault current increase and fault contribution due to DGs. The traditional fault current calculation/estimation methods based on feeder impedance may not work because power electronics interfaced DGs cannot be simply replaced by a simple voltage source like the traditional synchronous generators. During the grid-connected operation, DGs should be modeled as a constant power source, while during islanding operation, they behave like a voltage source with variable internal impedance. Our case studies have shown that DG can alter fault current contribution and one feeder may contribute fault current to a fault at a different feeder, which normally does not happen in the traditional distribution system. Therefore, careful re-evaluation and coordination of relay protection are necessary for microgrids.

\section{CONCLUSION}

The customer-driven microgrid is a promising concept in several fronts because it (1) provides means to modernize today's power grids by making it more reliable, secure, efficient, and de-centralized; (2) provides systematic approaches to utilize diverse and distributed energy sources for DG; and (3) addresses how to utilize DG more efficiently and more effectively and provides more reliable and greener power to customers. Power electronics is the enabling technology as power electronics interfaced DG and power electronics based control devices can make the customer-driven microgrid possible and at the same time can provide many ancillary services to the mains power grid [33]. To implement all these novel features, a number of issues related to DG's control and protection have been discussed in this paper. There are still a wealth of issues and challenges to be explored. 


\section{REFERENCES}

[1] A. P. S. Meliopoulos, "Challenges in simulation and design of microgrid," Proc. IEEE Power Engineering Society Winter Meeting, 2002, pp. 309-314.

[2] J. M. Carrasco, L. G. Franquelo, J. T. Bialasiewicz, E. Galvan, R. C. P. Guisado, M. A. M. Prats, J. I. Leon, and N. Moreno-Alfonso "PowerElectronic Systems for the Grid Integration of Renewable Energy Sources: A Survey," IEEE Trans. Power Electron., vol. 53, pp. 10021016, Aug. 2006.

[3] R. Lasseter, "Microgrids," Proc. IEEE Power Engineering Society Winter Meeting, 2002, pp. 305-308.

[4] R. A. Panora, J. B. Gehret, and P. Piagi, "Design and Testing of an Inverter-Based Combined Heat and Power Module for Special Application in a Microgrid," Proc. IEEE Power Engineering Society General Meeting, 2007, pp.1-8.

[5] Y. Ito, Y. Zhongqing, and H. Akagi, "DC Microgrid Based Distribution Power Generation System," Proc. IEEE International Power Electronics and Motion Control Conference-IPEMC, 2004, pp. 1740-1745.

[6] S. Chakraborty, M. D. Weiss, and M. G. Simoes, "Distributed Intelligent Energy Management System for a Single-Phase High-Frequency AC Microgrid," IEEE Trans. Ind. Electron., vol. 54, pp. 97-109, Feb. 2007.

[7] F. Blaabjerg, Z. Chen, and S. B. Kjaer, "Power Electronics as Efficient Interface in Dispersed Power Generation Systems," IEEE Trans. Power Electron., vol. 19, pp. 1184-1194, Sept. 2004.

[8] D. Candusso, L. Valero, and A. Walter, "Modeling, control and simulation of a fuel cell based power supply system with energy management," Proc. IEEE IECON, 2002, pp. 1294-1299.

[9] Y. Xue, L. Chang, S. B. Kjaer, J. Bordonau and T. Shimizu, "Topologies of Single-Phase Inverters for Small Distributed Power Generators: An Overview," IEEE Trans. Power Electron., vol. 19, pp. 1305-1314, Sep. 2004.

[10] F. Z. Peng, "Z Source Inverter," IEEE Trans. Ind. Applicat., vol. 39, pp. 504-510, Mar./Apr. 2003.

[11] F. Z. Peng, "Recent Advances and Applications of Power Electronics and Motor Drives -Power Converters' Recent Advances and Applications," IEEE IECON Proceedings, Nov. 2008.

[12] Y. W. Li, D. M. Vilathgamuwa, and P. C. Loh, "Design, Analysis and Real-Time Testing of Controllers for Multi-Bus Microgrid System," IEEE Trans. Power Electron., vol. 19, pp. 1195-1204, Sep. 2004.

[13] F. Katiraei, and M. R. Iravani, "Power Management Strategies for a Microgrid with Multiple Distributed Generation Units," IEEE Trans. Power Syst., vol. 21, pp. 1821-1831, Nov. 2006.

[14] D. N. Zmood, D. G. Holmes and G. H. Bode, "Stationary frame current regulation of PWM inverters with zero steady-state error," IEEE Trans. Power Electron., vol. 18, pp. 814-822, Mar. 2003.

[15] P. Mattavelli, "Synchronous-frame harmonic control for highperformance AC power supplies," IEEE Trans. Ind. Applicat., vol. 37, pp. 864-872, May/Jun. 2001.

[16] F. Blaabjerg, R. Teodorescu, M. Liserre and A. V. Timbus, "Overview of Control and Grid Synchronization for Distributed Power Generation Systems," IEEE Trans. Ind. Electron., vol. 53, pp. 1398-1409, Oct. 2006.

[17] G. K. Andersen, C. Klumpner, S. B. Kjaer, and F. Blaabjerg, "A new green power inverter for fuel cells," Proc. IEEE PESC, 2002, pp.727733.

[18] M.C. Chandorkar, D. M. Divan, and R. Adapa, "Control of parallel connected inverters in standalone AC supply systems," IEEE Trans. Ind. Applicat., Vol. 29, pp. 136-143, Jan/Feb 1993.

[19] N. Pogaku, M. Prodanovic, and T. C. Green, "Modeling, Analysis and Testing of Autonomous Operation of An Inverter-Based Microgrid," IEEE Trans. Power Electron., vol. 22, pp. 613-625, Mar. 2007.

[20] Y. W. Li, "Control and Resonance Damping of Voltage Source and Current Source Converters with LC Filters," IEEE Trans. Ind. Electron., in press, 2009.

[21] M. N. Marwali, J.-W. Jung, and A. Keyhani, "Control of Distributed Generation Systems-Part II: Load Sharing Control," IEEE Trans. Power Electron., vol. 19, pp. 1551-1561, Nov. 2004.

[22] M. Dai, M. N. Marwali, J.-W. Jung, and A. Keyhani, "Power Flow Control of a Single Distributed Generation Unit," IEEE Trans. Power Electron., vol. 23, pp. 343-352, Jan. 2008.

[23] C.-C. Hua, K.-A. Liao, and J.-R. Lin, "Parallel Operation of Inverters for Distributed Photovoltaic Power Supply System," Proc. IEEE PESC, 2002, pp.1979-1983.

[24] K. D. Brabandere, B. Bolsens, J. V. D. keybus, A. Woyte, J. Driesen, and R. Belmans, "A Voltage and Frequency Droop Control Method for
Parallel Inverters," IEEE Trans. Power Electron., vol. 22, pp. 11071115. Jul. 2007

[25] Y. Li and Y. W. Li, "Decoupled power control of DG units in a power electronics interfaced low voltage microgrid," Proc. IEEE IPEMC, 2009 , in press.

[26] J. M. Guerrero, J. Matas, L. G. Vicuna, M. Castilla, and J. Miret, "Decentralized Control for Parallel Operation of Distributed Generation Inverters Using Resistive Output Impedance," IEEE Trans. Ind. Electron., vol. 54, pp. 994-1004, Apr. 2007.

[27] J. M. Guerrero, L. G. Vicuna, J. Matas, M. Castilla, and J. Miret, "A wireless controller to enhance dynamic performance of parallel inverters in distributed generation systems," IEEE Trans. Power Electron., vol. 19, pp. 1205-1213, Sept. 2004.

[28] Y. W. Li and C. N. Kao, "An Accurate Power Control Strategy for Inverter Based Distributed Generation Units Operating in a Low Voltage Microgrid," Proc. IEEE ECCE, 2009, in press.

[29] Y. W. Li, D. M. Vilathgamuwa and P. C. Loh, "A Grid-Interfacing Power Quality Compensator for Three-Phase Three-Wire Microgrid Applications," IEEE Trans. Power Electron., vol. 21, pp. 1021-1031, Jul. 2006.

[30] A. Tuladhar, H. Jin, T. Unger, and K. Mauch, "Control of Parallel Inverters in Distributed AC Power Systems with Consideration of Line Impedance Effect," IEEE Trans. Ind. Applicat., Vol. 36, pp. 131 -138, Jan/Feb 2000.

[31] I. J. Balaguer, H-G Kim, F. Z. Peng, and E. I. Ortiz, "Survey of Power Systems Islanding Detection Methods," IEEE/IECON Proceedings, pp. 2247-2252, 2008.

[32] Irvin J. Balaguer; Uthane Supatti; Qin Lei; Nam-Sup Choi; Fang Z. Peng, "Intentional Islanding Operation of Microgrids," IEEE International Conference on Sustainable Energy Technologies (ICSET2008).

[33] F. Z. Peng, "Guest Editorial of Special Issue on Distributed Power Generation," IEEE Transactions on Power Electronics, Special Issue on Distributed Power Generation, vol. 19 no. 5, pp. 1157-1158, Sep. 2004.

Fang Zheng Peng (M'92-SM'96-F'05) received the B.S. degree in electrical engineering from Wuhan University, China, in 1983 and the M.S. and Ph.D. Degrees in electrical engineering from Nagaoka University of Technology, Japan, in 1987 and 1990, respectively. He joined Toyo Electric Manufacturing Company, Ltd., from 1990 to 1992 as a research scientist, was engaged in research and development of active power filters, flexible ac transmission systems (FACTS) applications and motor drives. From 1992 to 1994, he worked with Tokyo Institute of Technology as a Research Assistant Professor, initiated a multilevel inverter program for FACTS applications and a speedsensorless vector control project. From 1994 to 2000, he worked for Oak Ridge National Laboratory (ORNL), as a Research Assistant Professor at University of Tennessee, Knoxville from 1994 to 1997 and was a staff member, Lead (principal) Scientist of the Power Electronics and Electric Machinery Research Center at ORNL from 1997 to 2000. In 2000, he joined Michigan State University as an Associate Professor and now a full professor.

Yun Wei Li (S'04-M'06) received the B.Eng. degree from Tianjin University, China, in 2002, and the Ph.D. degree from Nanyang Technological University, Singapore, in 2006. In 2005, Dr. Li was a Visiting Scholar with the Institute of Energy Technology, Aalborg University, Denmark. From 2006 to 2007, he was a Postdoctoral Research Fellow in the Department of Electrical and Computer Engineering, Ryerson University, Canada. After worked with Rockwell Automation Canada in 2007, Dr. Li has been an Assistant Professor with the Department of Electrical and Computer Engineering, University of Alberta, Canada. His research interests include distributed generation, microgrid, power quality, power converters and electric motor drives.

Leon M. Tolbert (S'89-M'91-SM'98) received the B.E.E., M.S., and Ph.D. degrees in electrical engineering from the Georgia Institute of Technology, Atlanta, in 1989, 1991, and 1999, respectively. He joined Oak Ridge National Laboratory (ORNL) in 1991 and worked on several electrical distribution projects at the three U.S. Department of Energy plants in Oak Ridge, TN. In 1997, he became a Research Engineer in the Power Electronics and Electric Machinery Research Center at ORNL. In 1999, he was appointed as an Assistant Professor in the Department of Electrical and Computer Engineering, University of Tennessee, Knoxville, where he is currently an Associate Professor. He is an Adjunct Participant at the Oak Ridge National Laboratory and conducts joint research at the National Transportation Research Center. He does research in the areas of electric power conversion for distributed energy sources, motor drives, multilevel converters, hybrid electric vehicles, and application of $\mathrm{SiC}$ power electronics. He is a Registered Professional Engineer in the State of Tennessee. 